\title{
A ÚLTIMA CRISE: desde o colapso de Lehman Brothers até a questão da dívida pública europeia
}

\author{
Francesco Schettino \\ Seconda Università di Napoli
}

A ÚLTIMA CRISE: desde o colapso de Lehman Brothers até a questão da dívida pública europeia

Resumo: Este trabalho investiga as causas, a evolução e as perspectivas da crise econômica desde o colapso do Lehman Brothers, até a atualidade, isto é, a crise da dívida dos países do sul da União Europeia. Por meio do instrumental teórico marxista, o artigo explica as razões pelas quais tal crise pode ser considerada crise capitalista típica, uma vez que a superprodução e a queda relativa da taxa de lucro são fatores comuns na parte predominante do mundo. Desta forma excluímos drasticamente a interpretação de alguns pesquisadores que sustentam sua natureza financeira atribuindo a responsabilidade ao comportamento de um pequeno número de capitais (agências de rating etc.). Ao interpretar a evolução atual da crise pela guerra intracapitalista, mostramos como o capital, atrelado ao dólar, desencadeou as principais consequências da crise - originada nos EUA na década de Setenta do séc. XX - nos países da UE.

Palavras-chave: Crise capitalista, queda da taxa de lucro, dívida da EU.

THE LAST CRISIS: since the collapse of Lehman Brothers to the European public debt issue

Abstract: This paper inquires on the causes, the evolution and the perspectives of the economic crisis since the collapse of Lehman Brothers, until the actuality, i.e. the debt crisis of the southern countries of European Union. By means of Marxian theoretical tools the article explains the reasons which this crisis can be considered as a typical capitalistic crisis, once that the overproduction and the relative fall of the profit rate are common factors in the prevalent part of the world. In this way we drastically exclude the interpretation of some researchers sustaining its financial nature assigning the responsibility to the behavior of a few number of capitals (rating agencies). Giving an interpretation of current evolution of the crisis by means of the intra-capitalistic battle, we show how the capital linked to the dollar, overthrew the main consequences of the crisis - originated in the U.S. in the ' 70 s, in the twentieth century - on the EU countries.

Keywords: Capitalist crisis, fall of rate of profit, European debt. 


\section{INTRODUÇÃO}

Chegamos ao enésimo ano de recessão na maioria dos países de capitalismo avançado, e dificilmente encontraremos alguém, mesmo entre os mais convencidos e fieis apologistas do modo de produção atual e de suas lógicas, que ainda se atreva a falar em crise passageira, momentânea e a sustentar eufemismos parecidos. De resto, os dados mais recentes que dizem respeito à situação dos Piigs ${ }^{1}$, e da inteira eurozona, perfilam um quadro do futuro, no mínimo, obscuro. A Grécia já mergulha no abismo; o empréstimo de 130 bilhões de $€$ concedido em início de 2012, tanto exaltado pelo capital financeiro e pelos relativos agentes da imprensa, servirá apenas a permitir o reembolso, pago pelos trabalhadores gregos, de parte dos empréstimos contraídos pelo Estado grego com bancos e indústrias estrangeiras (alemãs e francesas in primis).

A perspectiva de uma falência pilotada para a Grécia já se dá como inevitavelmente subentendida (sem que isto implique necessariamente numa saída do País da união monetária); a única incógnita, por enquanto, é apenas a data do colapso e de suas consequências sobre todo o capital ligado ao euro e, portanto, sobre os capitais ligados respetivamente ao dólar e às moedas asiáticas. A frente italiana, doutro lado, não deixa prever resultados mais brilhantes dos desempenhados pelo país helênico: há uma semelhança de pontos de vista sobre o fato de que, se tudo der certo, a produção interna bruta italiana cairá no ano 2013 mais de um ponto percentual $^{2}$, determinando fortes repercussões sobre os trabalhadores (desempregados ou empregados de diversos tipos) com todo respeito ao otimismo propagandeado para quem impôs lágrimas e extraiu sangue das massas já de joelhos, através das políticas de austeridade. Pior que a Itália continua sendo a situação geral das economias da península ibérica consideradas, inclusive pelas agências de rating, como elos mais fracos e com alto risco de default no tabuleiro europeu (além de, obviamente, Grécia e Chipre). Por estas e outras razões ainda, ouvimos hoje velhos e novos acadêmicos - que até 2008 exaltaram, ideologizando desta forma milhares de estudantes, o perfeito sistema econômico do insulso Say (precursor da escola neoclássica) dizerem que os últimos terríveis quatro/cinco anos poderiam não ser atribuíveis a uma momentânea e cíclica depressão, mas a uma verdadeira crise sistêmica.

Além das singulares peculiaridades das fantasiosas teorias espalhadas tanto no âmbito universitário como na divulgação popular - desde o decrescimento feliz até os mirabolantes modelos econométricos que prefiguram a virtuosa saída do euro dos países do Sul da Europa -, é significativo notar que, o que une todos estas novas abordagens, é a constante e precisa indiferença e ignorância da análise marxiana que, em realidade, é a única abordagem científica que detalhadamente analisou, identificando com precisão, tanto as razões como o desenvolvimento das crises capitalistas: esta ideológica distração de massas direcionou a atenção para uma improfícua caça aos bodes expiatórios.

Contam-se talvez uma centena de causas da crise identificadas por improvisados especialistas; e isto determinou que a classe subalterna - ou seja, a que naturalmente está sofrendo de maneira mais dramática os efeitos da crise - ficasse em uma situação de total confusão por causa de tal hiperinformação (que, como se sabe é sinônimo de desinformação), inclusive distorcida, no momento em que não consegue compreender minimamente a origem de seu desespero (GIACCHÉ, 2011). Doutro lado, seria em absoluto contrário à missão de tais funcionários do capital admitir que o natural desenvolvimento do modo de produção é o que produziu a crise, e o que vivemos não é um acaso, mas a regra: a justificativa baseada em causas exógenas é, portanto, completamente instrumental, voltada a não provocar arranhões no perfeito equilíbrio do sistema, que o capitalismo, ao contrário, só pode garantir se for deixado livre de agir. Portanto, longe de querer apresentar a realidade em si, por meio de uma verdadeira caça às bruxas todos os agentes do capital identificaram, com ritmo incessante, pelo menos cerca de cinquenta presumidas cepas da doenças, obviamente todas desmentidas em breve.

\section{O JANTAR DE MANHATTAN E O ABISMO GREGO}

Era um inverno entre os mais rigorosos das últimas décadas. Manhattan já não era mais a ilha dos sorrisos plastificados, e das festas nos exclusivos apartamentos da burguesia nova-iorquina; ali, também, iniciavam a sentir-se e, sobretudo, a ver-se os efeitos devastadores da crise após o colapso de Lehman Brothers. Mendigos e sem teto já não se limitavam aos bairros marginais, mas como velhos fantasmas de uma economia capitalista em ascensão, iniciavam a tomar forma, a materializar-se em carne e osso, mostrando a todos a crua realidade do modo de produção atual. É exatamente nesta atmosfera que queremos imaginar este jantar, à base de frango assado ao limão e filés de primeira escolha, no dia 8 de fevereiro de 2010, no apartamento de um broker local (Monness, Crespi, Hardt \& co.) a que participam diversos gurus da finança "euamerikana", entre os maiores e mais perigosos terroristas dos trabalhadores do mundo inteiro: os representantes (os "homens") de Soros Group, de Sac Capital, de Greenlight Capital, de Brigade C. e da Paulson \& Co., (a não ser confundido com o ex-secretário 
do Tesouro de Bush jr, ademais diretor executivo, em um recente passado, de Goldman-Sachs, mas segundo algumas fontes alinhado contra a operação especulativa) (PULLIAM et al, 2010).

Embora os nomes citados não consigam contar por completo as ávidas potencialidades que atrás deles se escondem, com certeza, cada vez que eles se reúnem, a vida de milhões de trabalhadores é gravemente ameaçada, porque, sendo estes senhores os mais importantes gestores dos hedge fund (os fundos de cobertura), fica evidente que cada convergência de objetivos entre eles pode determinar verdadeiras tempestades em qualquer mercado de qualquer país.

Os movimentos em bloco deste capital fictício, ou seja, de uma forma peculiar de (não) existência do capital mesmo, demonstraram sua capacidade de detonação desde as crises de fim da década de Noventa (PALA, 1997),(México, tigres asiáticos, Rússia e Brasil). E por esta razão cabe lembrar que a esta especulação, que corresponde à fase alta do ciclo da crise de superprodução, participa o capital em sua totalidade, não somente o capital mau, parasitário. Constituem capital fictício, portanto, os chamados produtos derivados que estão à base de recentes explosões e colapsos nos negócios da bolsa. Trata-se apenas, sinteticamente, de apostas sobre oscilações e avaliações futuras (contratos a termo, opções de pagamento com prazos diferidos entre preços de compra e venda, calculadas eventualmente não sobre títulos particulares, mas sobre os índices oficiais das principais bolsas internacionais, vendas a descoberto, etc.). Claramente, tais apostas quase sempre são efetuadas sem ter dinheiro no bolso: isto provoca as chamadas bolhas especulativas.

Naquela segunda-feira de fevereiro, como já detalhadamente relevado pelo Wall Street Journal, estes personagens decidiram que estava na hora de assaltar: contudo, em evidente descontinuidade com o passado, cabe ressaltar que desta vez o objetivo não era representado pelas economias dos países do Terceiro mundo, mas pelos apêndices mais fracos da eurozona, evidenciando assim o recrudescimento, agora explícito, do conflito existente, desde quase uma década, entre os capitais pertencentes a áreas monetárias contrapostas (euro e dólar) e que caracteriza o imperialismo na fase atual (de que falaremos mais adiante) Através do instrumento dos credit default swap (um dos produtos financeiros derivados mais difusos) estes sicários do capital decidiram atingir pesadamente as economias dos países que hoje são definidos, com menosprezo, de Piigs, em inglês, porcos: Portugal, Irlanda, Grécia, Espanha e Itália.

A assim dita ideia do jantar [the idea dinner], ao que parece, consistiu em investir pesadamente sobre a desvalorização do euro que, desde o máximo alcançado em fim de 2009 de 1,5, \$, nas previsões do especuladores, poderia chegar a 1 \$ após uma arquitetada e simultânea ação voltada a entranhar- se nas contradições mais evidentes da área do euro, ou seja, a dívida dos países do sul do continente aderentes à moeda única. Pela reconstrução dos fatos, parece que foi justamente o chefe do fundo especulativo Brigade capital, Donald Morgan, a identificar no endividamento grego a brecha para inserir o aguilhão e determinar, ao seu dizer, um efeito dominó que deveria em breve tempo levar aos resultados esperados. A ideia deve ter convencido a todos os presentes porque, já durante a semana do jantar o volume de apostas na queda do euro alcançou o máximo, pelo que Morgan Stanley admitiu, de 60mil futures contratados. Não casualmente, somente algum dia após 8 de fevereiro, a taxa de câmbio com o dólar Eua alcançava o mínimo de $1,35 €$, registrando uma queda evidentemente manobrada por uma serie de operações muito bem planejadas e coordenadas. Doutro lado, pessoas como Soros, que explicitamente afirmava que o euro poderá sofrer um colapso a breve - há 18 anos havia dirigido a operação de especulação sobre a libra britânica embolsando ao fim de jogo cerca de um bilhão de dólares de lucros, impondo à Inglaterra a saída do mecanismo europeu das taxas de câmbio, com consequente e até demasiado previsível massacre das condições de vida dos trabalhadores do país (PASQUINELLI, 2010).

A onda de especulação contra os países da eurozona dos primeiros meses de 2010 foi erroneamente definida poralguns-eideologicamente por muitos outros - de nova crise. Este tipo de colocação da questão pressuporia a existência de uma velha crise com evidente referimento aos acontecimentos dos meses sucessivos ao colapso (dirigido e, portanto, deste ponto de vista, diferente da crise atual) de Lehmann Brothers; com apenas um mínimo de esforço de análise - infelizmente já efetuado por quem a crise, a crise verdadeira, do trabalho, está pagando na pele - é bastante banal, mas nem por isto óbvio, chegar à conclusão de que a raiz do que aconteceu, até agora, na Grécia, e mais em geral na Europa, seja a mesma que provocou o forte choque de fim de 2008, fazendo vacilar violentamente a inteira fundação do modo de produção capitalista; até mesmo Trichet, em 8 de maio de 2010 , definiu em sede oficial a situação atual crise de sistema (REDAZIONE, 2010). Tratase, portanto, da mesma crise de superprodução, vinculada à queda da taxa de lucro, que de um lado acelera incrivelmente as tentativas especulativas e, por outro, acirra o terreno de confronto entre os capitais que pertencem a fileiras produtivas de campos imperialistas contrapostos. Sem entrar numa análise detalhada da crise geral do capital - iniciada na década de Setenta com a anulação dos acordos de Bretton Woods - alternando fases de expansão a fases de recessão mais fortes, mas desenvolvendo assim uma tendência à queda, é importante lembrar que esta é a única responsável pelo colapso financeiro dos Estados em questão 
(PALA, 1981). Com demasiada frequência, diante da emergência de eventos como os atuais que estão assolando a ordem econômica e institucional do velho continente, muitos especialistas, inclusive quem se define marxista, se agitam na caça às bruxas tentando descobrir o bode expiatório, na perversa lógica de tentar isolar a hipotética maçã podre (neste caso os especuladores) que estragaria as outras que, ao invés, seriam sadias.

Nesse contexto, os chamados especuladores sem escrúpulos - mais corretamente o capital fictício - foram identificados como os principais responsáveis da questão, como se existissem especuladores escrupulosos (evidente oximoro) ou como se tivesse sentido efetuar uma distinção entre capital bom e capital ruim. Esta tipologia de separação é, além de errônea, fortemente enganosa, porque se resolve na infundada acusação contra um não bem definido liberalismo sem freios (isto pressuporia a existência de um liberalismo bom, talvez com o freio de mão puxado...) e à consequente hipótese de políticas ad hoc, como o não-conceito abusado de regulamentação dos mercados (financeiros, do trabalho, etc.) que potencialmente travariam e preveriam estes fenômenos. O aval a estas posições significa completa ignorância do modo de produção capitalista, em sua contraditória unicidade e multiplicidade e de seu geral e particular funcionamento. O objetivo do capital, com efeito, é a acumulação, que pode acontecer com ou sem a produção de valor: como lembra Marx - já que a produção do capital se diferencia dos precedentes modos de produção exatamente para ter em seus fundamentos a finalidade da troca e não do uso dos produtos (ENGELS; MARX, 1846) - a mercadoria mesma, em típico processo global de produção e circulação, a fórmula dinheiro-mercadoria-dinheiro valorizado pode tornar-se, nos momentos de crise, um empecilho para a acumulação, um lastro que qualquer capital preferiria jogar fora através de fenômenos de especulação, reduzindo a fórmula aos seus dois polos extremos, dinheiro-dinheiro valorizado, dinheiro que cria mais dinheiro (MARX, Teorie sul plusvalore, q.xv, pp.891 ss; Il Capitale, I.24).

Um dos fatores que inibe os muitos pequenos capitais, só aparentemente mais humanos, mergulharem em ações especulativas é que, sendo o jogo da bolsa um jogo a soma zero, se não se consegue arrancar aos outros capitalistas as cotas de mais-valia produzidas alhures, inevitavelmente, sucumbe-se: não há nada de "ética" ou outros devaneios parecidos nisto. Na realidade, já realçava Marx há um século e meio atrás:

[...] com o desenvolvimento do comércio e da produção capitalista, que produz unicamente para a circulação, a base natural do sistema de crédito se amplia se generaliza, se aperfeiçoa. De todas essas formas, entretanto, o capital produtivo a juros constitui o fetiche mais completo (MARX, II Capitale, III-25),

Onde a formula [D-M-D'] é reduzida a [DD'], em que o capital enquanto portador de juro composto, aparece como "um Moloch que exige o mundo” (MARX, Gründrisse, 2.29).

Estamos assim diante da "completa retificação, da virada pelo avesso, da loucura do capital enquanto capital produtivo a juros - em que, entretanto, se manifesta a íntima natureza da produção capitalista, sua loucura, na forma mais tangível" (MARX, Teorie sul plusvalore, Appendice: il reddito e le sue fonti; l'economia volgare, III;1-5).

Já é intrínseco à etimologia mesma do capital fictício o conceito de aparência, de simulação: sendo o andamento dos preços dos títulos cotados nos mercados da bolsa prevalentemente baseado em verdadeiras apostas sobre o preço, é trivial observar como, globalmente, seja quase completamente desvinculado de qualquer relação com o valor produzido e existente e, mais ainda, não determine de forma mais absoluta, a criação de novo valor, usando somente uma aparente, e, portanto, inexistente, nova riqueza: observava Marx que

[...] a diminuição ou o aumento de valor destes títulos são independentes do movimento de valor do capital real que eles representam, a riqueza de uma nação não varia em consequência de tal diminuição ou aumento. Como sua desvalorização não exprime um efetivo arresto na produção, a nação não resulta empobrecida em um centavo, em seguida ao estouro dessas bolhas de sabão de capital monetário nominal (MARX, II Capitale, III-29).

Tratando-se, portanto, de um articulado e complexo sistema baseado na interação de avaliação de diversos operadores sobre o andamento dos preços, absolutamente distintos da base de produção (o valor) - que fica por consequência absolutamente inalterada -, é claro que a regra do jogo consista justamente na determinação dos apostadores, cujas potencialidades de ganho (ou perda) apoiam unicamente no relativo erro (ou justeza) das previsões de seus concorrentes: em síntese excluindo por enquanto aumentos generalizados e artificiosos dos títulos de ações, as chamadas bolhas - o ganho dos especuladores "ganhadores" é igual à soma das perdas de quem sai derrotado do jogo. O mesmo discurso vale para as agências de rating que nas últimas semanas conquistaram as primeiras páginas dos diários do mundo inteiro: elas são instrumentos afiados nas mãos de quem 
tem a possiblidade de falsificar o preço dos pacotes de ações que são vendidos como se possuíssem um alto valor, até os compradores descobrirem que se trata de lixo (junk bonds). Para além da evidente desonestidade destes avaliadores, atribuir a eles a responsabilidade da crise, seria como considerar a lâmina excessivamente afiada da faca como a verdadeira responsável por um homicídio: ou seja, confunde-se o ator com o instrumento.

A evidente potencial insolvência do estado grego, portanto, foi o pretexto que estimulou um inevitável rebaixamento dos títulos de estado (junk bonds), o que determinou imediatamente uma queda de seu valor, ou seja, uma drástica redução da riqueza fictícia dos possuidores deste tipo de títulos - principalmente os bancos europeus (ZETTELMEYER et al., 2012) que desencadeou o pânico nos principais mercados bolsistas. Em particular, cabe ressaltar como grande parte dos empréstimos, que nos últimos anos fizeram crescer de maneira tão evidente o endividamento do Estado grego, derivou dos bancos alemães ligados ao governo alemão e garantidos pelo eixo político MerkelKaramanlis. Nesta perspectiva, por conseguinte, deve-se interpretar o fluxo de empréstimos fornecido pela UE à Grécia (e naturalmente pago pelos trabalhadores de todo o continente): permitir aos credores amigos a restituição de pelo menos parte do crédito já oferecido. A tal respeito é significativo ressaltar que o mecanismo de garantia da dívida soberana em sofrimento esteja atado a um percurso perverso que dificilmente será possível desatar. Quando após a falência de Lehman Brothers, os estados intervieram para salvar muitos bancos europeus e estadunidenses, eles foram financiados principalmente pelos mesmos bancos que estavam à beira do abismo! Não por acaso, exatamente entre o fim de 2008 e início de 2009 , os institutos de crédito europeus compraram 357 bilhões de $€$ em títulos de estado, chegando a possuir um total de 1552 bilhões $€$, valor exorbitante, até mesmo superior ao inteiro PIB da Itália em 2012.

Seria, portanto, correto perguntar-se como puderam, bancos à beira do abismo, adquirir um montante de títulos tão oneroso: a resposta, aparentemente absurda, mas compatível com as lógicas de resgate de um modo de produção que já chegou a seus próprios limites, encontra-se no empréstimo que a BCE em maneira realmente gratuita ( $1 \%$ de taxa de juros nominal) concedia sem limites a estes sujeitos que de um lado podiam assim garantir seus próprios créditos, adquirindo as dívidas de seus devedores (isto mesmo, entenderam bem!), do outro lado embolsavam milhões de euros equivalentes às taxas pagas pelos títulos da dívida pública através da transferência do salário direto (imposição fiscal).

Contudo, cabe lembrar mais uma vez, o problema é muito mais extenso e envolve o inteiro modo de produção capitalista: convém, portanto, lembrar a situação de endividamento que geralmente aperta todos os estados do mundo. Cumulando as dívidas (privadas e públicas) de EUA, Inglaterra, Japão e Canadá, chega-se a um importo de 130 trilhões \$ (dados de fim 2012) que, para tornar isto mais compreensível, é o dobro do inteiro valor da produção de mercadorias no mundo inteiro. Disto, cerca da metade é euamerikana, enquanto o total das dívidas dos estados europeus amonta a 40 trilhões \$: diante destas somas, evidentemente, os 300 bilhões $€$ da dívida helênica constituem uma entidade irrisória, e isto demonstra mais uma vez que a situação grega não representa de per si um problema insuperável, particularmente na ótica da desestabilização da inteira eurozona, apesar dos problemas já evidenciados. Para sustentar isto, deve-se notar que também do ponto de vista da crise imobiliária, a Grécia foi um dos países menos afetados pela expansão da bolha que, ao contrário, em outros países da Europa (em particular Espanha, Irlanda, Portugal e Itália) e EUA foi significativa.

O problema está, ao contrário, no fato de que, para sustentar taxas de acumulação que o mercado capitalista, por sua natural finitude - que se choca contraditoriamente com a ruim infinidade da produção capitalista - não garanta mais, há décadas, os agentes do capital encherem e, portanto, alterarem artificiosamente, a riqueza fictícia mundial como um imenso balão aerostático por meio de mecanismos fiduciários e apostas que se mantêm no fio da navalha no momento em que um dos irmãos inimigos decidir atacar um dos elos mais fracos, como em uma cadeia de Santo Antônio, todos os possuidores de títulos de valor inexistentes acabam ficando com um monte de lixo em seus orçamentos (por exemplo os títulos da dívida dos Piigs) e tocam com mão a possibilidade de iminente falência. Para representar a economia capitalista pode ser útil a metáfora do equilibrista, que, até quando a corda segurar, pode caminhar até mesmo por quilômetros, mas à primeira hesitação, ou ao primeiro forte golpe de vento está sujeito a uma queda que Ihe impedirá retomar ao seu normal percurso

O capitalismo mundial encontra-se, portanto, em uma condição crítica, e, por isso, diante de uma evidente contração da produção real mundial, deve enfrentar um aumento, absoluto e mais ainda relativo (a alavanca financeira), da riqueza fictícia possuída por cada um - capitalistas e famílias (veja-se, por exemplo, as fraudes dos fundos de pensão) - que se mantém de pé somente por causa de um precário clima de confiança suscetível de vir a faltar a qualquer momento. Os mecanismos de "resgate" acontecem justamente em função de um simples deslocamento das dívidas (o chamado refinanciamento) a sujeitos que são, eles mesmos, altamente endividados, mas que mostram uma estabilidade maior dos que entraram em crise: a situação é tão contorta e desgastada que é suficiente um devedor aparentemente mais confiável assumir 
as dívidas de um em dificuldade para estabilizar o humor dos mercados financeiros. Doutro lado, em uma condição de crise generalizada, a estratégia de atingir e fugir (hit and run) torna-se de central importância. Como complemento, porém, atuam políticas de austerity que essencialmente consistem em piorar drasticamente o valor de troca da forçatrabalho (agindo tanto sobre o salário direto como sobre o indireto ou diferido) consentindo assim uma ulterior transferência de mais-valia da classe subalterna para a classe dominante. Contudo, como recentemente calculou uma agência de serviços financeiros, a McKinsey \& co., as operações de redução da dívida não são isentas de custos, inclusive para o capital em sua totalidade: na estreita prevalência dos casos (cerca de 45) que desde 1930, foram seguidas por uma recessão que durou em média duas ou três anualidades; em uma fase como a atual, as coisas poderiam até ser piores.

\section{A LANÇA E O ESCUDO}

O tímido otimismo dos operadores europeus no último trimestre de 2012 parece ter sido suplantado por um temor difuso de uma potencial reincidência dos mesmos problemas que tem apertado o capital ligado ao euro no biênio passado. A conflitualidade monetária (PALA, 2002; SCHETTINO, 2010) alcançou o acme no início de 2010, quando muitos, entre os agentes mais destacados do capital ligado à moeda americana decidiram cumprir um formidável ataque aos irmãos inimigos ligados à moeda única europeia. $O$ ataque foi lançado, através de uma ingente movimentação de instrumentos derivados, ao calcanhar de Aquiles do euro, ou seja, aos chamados piigs, e mais em particular ao país, entre eles, que além de uma situação de contas públicas comprometidas e falsificadas apresentava uma estrutura particularmente débil: a Grécia. Sucessivamente foi a vez de Itália e Espanha, cujo andamento do famoso spread tem sido um bom indicador do grau de especulação acumulado sobre os respetivos títulos da dívida pública.

$O$ resultado mais imediato foi de transferir de um lado (o estadunidense) ao outro (Europa) do Atlântico grande parte dos efeitos mais nefastos da explosão da crise que, cabe lembrar, emergiu nos Estados Unidos, país que ainda hoje se vangloria da dívida pública e privada mais elevada do mundo e que periodicamente se aproxima à beira do abismo. De qualquer forma, graças às possibilidades da Federal reserve (FED) de agir como prestador de última instância, ou seja, de imprimir moeda para financiar o governo através da compra direta de títulos da dívida pública federal, as políticas dos quantitative easing (QE), ou seja, da emissão de milhares de dólares em poucos anos (cerca de 2500 bilhões $\$$ nas primeiras duas tranches) tiveram seus efeitos. Gerando uma liquidez quase que gratuita, permitiram tanto aos grandes capitais de retomar ou alimentar suas operações - principalmente de natureza especulativa - como às empresas que, por sua desastrada situação não teriam acesso ao crédito ordinário porque incapazes objetivamente de fornecer garantias de restituição das somas de que necessitavam, de poder dispor de um pouco mais de oxigênio e de evitar, ao menos por um período de tempo limitado, o chamado credit crunch.

Na primeira parte de 2012 muitos apostariam no possível desaparecimento, em tempo curto, da moeda única europeia: em muitos, inclusive a imprensa bem acreditada junto à burguesia, afirmavam a eventualidade de prever um euro a duas velocidades, de modo que se pudessem desvincular os países mais fortes, Alemanha in primis, dos que encontravam dificuldade, em primeiro lugar os piigs. Embora as hipóteses se desenvolvessem a partir desta ideia, alcançavam frequentemente graus de absoluta absurdidade, estimuladas pela permanente incapacidade das instituições europeias de conseguir reagir a um fluxo de capital fictício tão forte e persistente. As chamadas políticas de austerity voltadas à redução da dívida, neste período iniciavam concretamente a gerar um quadro devastador no que diz respeito à condição dos trabalhadores - pondo, portanto, em risco a estabilidade social - e conseguindo, além disto, o difícil objetivo de aumentar o montante que ainda segue o signo negativo do andamento do PIB em quase a totalidade dos países mais endividados.

Talvez porque temorosos do fato de que diante de uma condição como esta os trabalhadores pudessem finalmente acordar, mas mais provavelmente para levantar-se de uma posição que os via objetivamente em grande dificuldade, os agentes do capital ligado ao euro, após um verão particularmente turbulento, decidiram utilizar um instrumento até então completamente excluído, exatamente pela ordem normativa existente. Quando o presidente da BCE, Draghi - homem de Goldman Sachs, sempre bom lembrar-se disto - declarou publicamente em julho de 2012 que faria de tudo em defesa do euro, então, muitos dos capitais que tinham conseguido lautos lucros através de operações especulativas contra os títulos da dívida pública dos estados europeus, compreenderam que algo poderia realmente mudar. Elaborou-se então um artificio que, ao menos em parte, desvinculou o BCE de quanto previsto pelo tratado - ou seja, de não poder agir como prestador em última instância; chama-se de plano OMT (Outright monetary transactions) e faz parte do SEM, ou seja, o mecanismo de estabilidade monetária, que, embora dotado de um fundo limitado ( 650 bilhões $€$ ) e por isto provavelmente inadequado diante dos potenciais atos de força especulativos, ao menos para o período que acabou de passar, garantiu um momentâneo afrouxamento da pressão sobre a dívida dos países mais fracos.

A relevância desta manobra, embora 
indiretamente, foi confirmada pelo quase contemporâneo contra-ataque adotado pela FED: provavelmente para fazer face à possibilidade que o foco da recessão pudesse voltar ao ponto de partida e de onde se alimentou fortemente, Bernanke, presidente da Federal Reserve, inaugurou a terceira onda de quantitative easing. Tal instrumento de política monetária garantirá a economia estadunidense na base anual de cerca de 1500 bilhões \$, uma soma que, além do mais, vale apenas como limite mínimo enquanto, se as condições do mercado de trabalho, e mais em geral, da produção, não devessem mostrar sinais de uma inversão de tendência, a FED terá o mandado de imprimir um número de notas quase que ilimitada (a manobra tem sido chamada, por esta razão, open ended). Se acrescentamos que contemporaneamente foi lançada a operation twist - que permite à FED de comprar títulos da dívida a longo prazo no valor de 85 bilhões $\$$ ao mês podemos compreender claramente que se o capital ligado ao euro dotou-se de um discreto escudo, o dólar não ficou para trás, afiando bem, ao contrário, as flechas do seu arco.

Os últimos meses de 2012 mostraram um andamento do mercado dos títulos da dívida pública dos Piigs significativamente mais estável: evidentemente esta forte tomada de posição por parte das autoridades europeias agiu, ao menos no imediato, como dissuasivo para com o capital fictício, sempre a espera para intervir e assolar a ordem política e econômica dos países aderentes à eurozona. Doutro lado, em uma fase em que o nível de acumulação do capital mundial se acomodou assintoticamente sobre o zero, não cai num negativo profundo somente pelo formidável crescimento da reconhecida primeira potência comercial mundial (a China), o grau de dureza com que se trava o conflito intercapitalista aumentou: a mesma decisão do BCE de criar um escudo remete claramente ao fato de que, em algum lugar, e nem muito longe, exista um exército com intenções nada pacíficas.

Todavia, diante de uma substancial melhora dos índices da bolsa - em muitas praças europeias e não somente aconteceu o fenômeno definido em termos técnicos rally de fim de ano - os resultados em termos de acumulação de capital foram geralmente na direção oposta. Em substância, enquanto os títulos da bolsa se comportavam como se a crise tivesse sido superada, a produção e a circulação das mercadorias ficaram paradas e em muitos países continuam a alimentar a tendência recessiva inaugurada já nos anos passados. Deste ponto de vista cabe ressaltar o fato de que o índice sintético Dow Jones, da mesma forma que seu homólogo nipônico, tenham até superado os valores (já inchados) registrados antes do colapso de Lehman Brothers. Somente alguns, entre eles até mesmo o diário italiano il Sole 24 ore (LONGO, 2013) evidenciaram de forma alarmante tal discrepância enquanto, com grande probabilidade esta poderia ser o efeito de um novo poderoso enchimento de uma ou mais bolhas especulativas. Doutro lado, somando as três ondas de QE da FED, e a quantidade de dinheiro emprestado a taxa de juros inferiores aos da inflação do BCE (que, portanto, dá dinheiro de presente aos privados a taxas reais negativas) o volume de liquidez injetado na economia mundial mastodôntico; e se, facilmente, se correlaciona esta imensa soma com a redução dramática da demanda pagante de um dos mercados mais relevantes do capitalismo o da EU, cuja renda global ainda é superior à dos EUA - não é ousadia imaginar que uma grandíssima parte desta liquidez, tornando-se capital e tendo portanto a necessidade de autovalorizar-se, diante de uma persistente armadilha de superprodução, prefira tentar lucrar no mercado financeiro, eludindo a passagem através da mercadoria e, portanto, da produção.

Deste ponto de vista é emblemática a situação da oitava economia mundial (em termos de PIB nominal, em 2011), ou seja, a Itália: considerando o fato de que, como se sabe, as medidas da taxa de desemprego subestimem fortemente a entidade do fenômeno, a superação do limiar de $11 \%$ é um fenômeno absolutamente alarmante. Além do mais, os resultados da pesquisa realizada por Confartigianato fornecem uma representação ainda mais aderente à realidade, mostrando como, em média, o capital localizado na Itália, tenha diariamente liberado 480 unidades de forçatrabalho entre o fim de 2008 e o fim de 2012. Não surpreende, então que a taxa de desemprego - ou seja, a cota de trabalhadores na faixa entre 15 e 65 anos - tenha chegado a um escarno $57 \%$ total $(46 \%$ para as mulheres) mostrando que, no ano apenso iniciado, globalmente, a força-trabalho ativa seja provavelmente inferior à não empregada. Se a isto acrescentamos os dados relativos à produção de mercadorias e à demanda pagante, obtém-se um quadro ainda mais assustador: no que diz respeito a esta última, o fato de o mercado do automóvel normalmente considerado como um bom indicador da economia em seu conjunto - ter se contraído a tal ponto que registrou em fim de 2012 um número de imatriculações próximo ao de 1979, é um elemento que já em si permite configurar da maneira adequada os status geral. Ou Esta intuição é confirmada com maior precisão do valor da produção industrial italiana, que alcançou o mesmo volume de 1990, contraindose em uma cota próxima de $25 \%$ e voltando atrás de vinte e três anos: uma verdadeira hecatombe de valor, provavelmente nunca observada no último século - com a exclusão dos períodos bélicos e os que os precederam e seguiram, que apenas em pequena medida poderia ter sido compensada por fenômenos de deslocamento produtivo.

Um quadro assim perfilado é efetivamente já de per si desastroso e alarmante: todavia é preciso acrescentar um ulterior elemento que, de fato, constitui a razão principal para a qual os refletores da 
Europa inteira estão voltados à Itália: os instrumentos contra os ataques especulativos disponibilizados pelo chamado fundo salva-estados, que discutimos precedentemente, estão condicionados pela adoção, por parte dos governos que pedem de acessar ao fundo das políticas de austeridade ditadas pela troika. Em ausência de uma garantia deste tipo, - BCE não poderá de fato agir de prestador de última instância, contrapondo-se a eventuais fluxos especulativos que provêm presumivelmente do capital ligado ao dólar; isto, potencialmente, poderia repropor condições muito próximas às que se apresentaram em fim de 2010 e em grande parte de 2011 em todos os Piigs. Desta vez, porém, a cair no abismo do capital fictício não seria a Grécia com seu limitado PIB e sua mais ainda insignificante dívida: a dívida pública italiana é de tamanhas proporções que um forte ataque especulativo poderia ter efeitos extremamente nefastos para toda a área do euro, prefigurando cenários, neste momento, absolutamente inimagináveis.

Por outro lado, também um dos outros países a maior risco, a Espanha, está vivendo uma fase politica extremamente delicada que poderia pôr em risco a estabilidade: o claro episódio de corrupção que recentemente envolveu o governo, embora não tenha provocado imediatamente novas eleições, certamente enfraqueceu a credibilidade dos partidos atualmente no parlamento espanhol e, em um futuro próximo poderia levar a uma situação análoga à italiana. Pior ainda é a situação de Chipre que, apesar da marginalidade substancial de sua economia, poderia gerar um efeito dominó de certa maneira parecido com o já experimentado nas primeiras fases da crise helênica. A este ponto, se os Piigs mostrassem de novo tal fragilidade, o capital fictício ligado ao dólar encontraria diante de si um autopista livre para golpear, desta vez, podendo realmente desestabilizar o coração do capital ligado ao euro com consequências que obviamente seriam particularmente duras para as classes subalternas locais.

\section{CONCLUSÃO}

O capital, desde as últimas quatro décadas ${ }^{6}$ está vivendo uma crise imanente que se concreta principalmente através da redução tendencial da margem de lucro, em consequência, sobretudo, do aumento do emprego de capital constante sobre o variável. As tentativas de resolver esta contradição, inúteis exatamente porque a contradição é imanente, se manifestam no primeiro ato deste drama ideal através da redução dos salários e, portanto, por meio da apropriação de uma cota maior de trabalho não pago durante o processo de produção imediata e a libertação de uma massa crescente de forçatrabalho que continua engrossando de maneira estupefaciente as fileiras do exército industrial de reserva. Em sua anárquica multiplicidade este método determina que a massa de mais-valia (e de valor) se possa encher tendencialmente ao infinito sem alguma garantia de que se realize no segundo ato - o da circulação - permitindo um adequado grau de acumulação.

$\mathrm{Na}$ asfixia provocada pela crise endêmica pela redução da taxa de lucro, estão os germes de outra contradição, igualmente grave e irresolvível, que está à sua base: o excesso de superprodução de capital e, portanto, de mercadorias. Em um período histórico em que a fome e a pobreza constituem problemas contra os quais cotidianamente combatem quase os $2 / 3$ da população mundial, isto parece um paradoxo, e se não se investigarem as razões, acabará estimulando reações emocionais contra o desperdício da sociedade consumista que é um conceito absolutamente moralista, desprovido de qualquer acepção científica. Com efeito, é justamente a natureza do modo de produção capitalista que permite que isso aconteça, especialmente quando, como aconteceu nos últimos anos, o ponto de saturação da demanda pagante parece cada vez mais próximo. O capital não tem como fim a satisfação das necessidades, mas a produção do lucro; o objetivo da produção das mercadorias é a troca e não o uso. Consequência disso é uma total ausência de planejamento da atividade - que ao contrário é anárquica - a que segue a natural tendência à monstruosa acumulação de mercadorias que em sua teórica infinidade bate contra a finitude do mercado mundial.

Portanto, a superprodução do "primeiro ato" torna-se um excesso se valor e mais-valia produzidos não se realizam no ato sucessivo. A razão disso tudo é ligada ao fato de que o

[...] modo de produção capitalista é somente um modo de produção relativo, que não tem limites absolutos, mas que se tornam tais em razão do modo de produção mesmo. Como seria possível que possa haver um defeito na demanda de mercadorias de que o povo necessita [...]? Exatamente porque somente neste nexo, especificamente capitalista, o produto em excesso veste tal forma que quem o possui pode pô-lo a disposição do consumo unicamente quando esta se reconverte para ele em capital (MARX, II capitale, III; 15).

Portanto, com o objetivo de extrair a máxima mais-valia da atividade de trabalho do operário, o capital, contraditoriamente, reduz cada vez mais o salário (ou seja, a capacidade de compra) e isso representa uma condenação quando as mercadorias chegarão ao mercado e não encontrarão uma adequada demanda pagante por causa da desigualdade distributiva que este mesmo estabelece. 
Neste sentido, a redução dos salários e, portanto, da capacidade de compra dos trabalhadores, é certamente um impedimento para a realização do valor e da mais-valia já produzida, piorando dramaticamente a situação crítica desencadeada pelo enorme excesso de mercadorias produzidas, Este tipo de dinamicidade contraditória, que nasce na fase da produção e se extrínseca na circulação, especialmente em períodos agudos de crise geral, pode provocar um significativo número de vitimas - tanto em termos de trabalhadores como em termos de capitais - e dar fortes sacudidas ao sistema capitalista mais em geral. Ciente da difusa incapacidade de compra dos assalariados - com boa paz da "soberania do consumidor" da teoria econômica burguesa - o capital tem tentado há muitos anos resolver o irresolvível, moldando um modo de ser que obrigue estes sujeitos a comprar, inclusive em ausência de condições materiais. Com uma propensão à poupança negativa já desde 2005, consumos reais que aumentam a um ritmo superior a $3 \%$ ano, dívidas privadas em crescimento tendencial de mais de $11 \%$ e uma relação entre passividade e renda disponível ânua de $126 \%$ (+31\% em relação ao crítico 2001), nos EUA, já há algumas décadas, as famílias gastam mais do que ganham e tendem cada vez mais a forçar esta tendência.

A práxis do endividamento há anos é difusa também no resto do mundo: próximos a $150 \%$ as famílias dos países de capitalismo avançado, como Japão, Austrália, e Reino Unido; as famílias residentes na Europa setentrional (encabeçados por Dinamarca e Holanda) estão próximas de uma taxa percentual às vezes superior a $200 \%$, o que mostra que o valor de suas compras é o dobro dos salários percebidos. Esse tipo de estratégia pode contar principalmente com o instrumento do fetichismo da mercadoria que, como qualquer outra forma de religiosidade, utilizou meios adequados a permitir a elevação espiritual. Pressionando sobre uma consciência de classe reduzida ao mínimo, tornou-se relativamente fácil conseguir impor esse tipo de conduta de vida que, escondendo suas próprias condições materiais, baseia-se na posse e na propriedade.

Mas esse tipo de estratégia também se depara às vezes com limites e obstáculos que emergem quando, como aconteceu nos últimos anos, torna-se necessário vender mercadoria sobre as quais o mesmo capital financeiro montou um ataque especulativo. Foi assim que, em razão da evidente impossibilidade de comprar pela maioria de trabalhadores estadunidense, os chamados operadores financeiros, com a obrigação de vender imóveis artificiosamente hipervalorizados, ofereceram financiamentos a pessoas objetivamente insolventes. A necessidade do dinheiro de ser utilizado como capital e, de outro lado, o vínculo da realização da mais-valia constituem os motivos que basicamente produziram a crise dos subprime (e não o contrário).
As razões de um comportamento especulativo assim aparentemente irracional é ele também ligado à saturação do mercado mundial que forçou até o limite os esforços dos capitais transnacionais na tentativa de resolver a irresolvível crise em que versa. A superprodução de capital e mercadoria determinou uma pletora de capital monetário ainda que esta última possa ser o fruto, talvez de momentâneas ausências de esferas de investimento. Sendo capital, e não renda, e tendo, dessa forma, o objetivo de produzir lucro, este é investido onde consegue valorizar-se, tornando-se autônomo da fase da produção imediata através da detração de cotas de mais-valia produzidas por outros capitais. Contudo, atualmente, as condições são ainda mais difíceis: a taxa de lucro geral está em queda livre - apoiada paradoxalmente pelo único grande país que se autodefine socialista, a China - e, também do ponto de vista especulativo, os riscos tornaram-se imensos porque o lucro ligado a tais atividades é limitado pela contração da acumulação real.

Em uma situação assim, não deve surpreender a escolha, profundamente contraditória, como vimos - de decidir em um primeiro momento de especular sobre a propriedade de imóveis e depois sobre as mercadorias de primeira necessidade gerando fome e causando a morte de milhões de indivíduos. O hábil acobertamento por parte dos capitais ligados ao dólar, através da criação de derivados sobre derivados, que oculta o real porte das ações vendidas, somente transferiu na Europa, pelo que parece, devastadores efeitos críticos provocados pelo estouro da imensa bolha especulativa dos imóveis estadunidenses. Isso não somente não resolveu a crise, que evidentemente se agravou, como tornou particularmente imprevisíveis seus êxitos.

Á luz da crise de acumulação que o capital mundial em seu conjunto está sofrendo, até o estímulo das causas antagônicas da crise estão se revelando menos eficiente de quanto previsível: a conflitualidade interna à classe proprietária, e ao mesmo tempo a transnacionalidade do capital estão, com efeito, tornando inúteis as diversas tentativas especialmente nos EUA e na Europa - de dar novo oxigênio aos lucros, cada vez mais ligados a injeções de liquidez estatais e aos menos eficientes escudos opostos contra-ataques especulativos. O volume das transações de capital fictício já superou em valor quase dez vezes a produção real de mercadorias criando uma imensa bolha que será praticamente impossível de esvaziar. Por enquanto, somente a doida corrida dos gigantes asiáticos (China, antes que Índia) está mantendo em vida um sistema que provavelmente não havia chegado a tal situação nem antes das duas guerras mundiais. Sem dúvida estamos atravessando uma passagem histórica da vida do modo de produção atual: quanto durará e aonde levará a humanidade, por enquanto é impossível de 
prever. Com certeza, o grande sujeito que continua ignorando os apelos à História é claramente a classe proletária. Sua inexistente organização ameaça relegá-la a uma subalternidade ainda mais pronunciada em comparação com quanto aconteceu nos anos de maior prosperidade de acumulação de capital. Doutro lado, o crescente fermento autoritário e despótico que, sobretudo em diversos países europeus está assumindo conotações cada vez mais preocupantes, embora disfarçado de forma diferente conforme cada especificidade, na fase atual poderia ser a única garantia para um capital mundial que chegou até seus próprios limites ${ }^{4}$ e novas formas de organização política e da produção, em sentido ainda mais coercitivo, poderiam representar a fronteira, desde que o lado mau da sociedade, o proletariado, não decida retomar sua marcha, escolhendo de tornar a expropriação dos expropriadores sua mesma razão de ser.

\section{REFERÊNCIAS}

ENGELS, F.; MARX, K. L'ideologia tedesca. Milan: Bompiani, 1846.

GIACCHÉ, V. La fabbrica del falso: Strategie della menzogna nella politica contemporanea. Roma: Derive e Approdi, 2011.

LONGO, M. I timori di ingovernabilità annullano l'effetto-Bce. [S. L.: s. N.], 2013.

MARX, K. II Capitale. [S. L.]: Editori Riuniti 1867.

Gründrisse. Lineamenti fondamentali della critica dell'economia politica. [S. L.]: Pigreco editore, 1858.

PALA, G. L'ultima crisi. [S. L.]: Franco Angeli, 1981.

Teorie sul plusvalore. [S. L.]: Editori Riuniti [ed.1993], 1861-1863.

PASQUINELLI M. Perche' il collasso della Grecia rischia di travolgere con l'Italia tutta eurolandia?. Disponivel em: <sollevazione.blogspot.com>. Acesso em: 11 fev. 2011.

PULLIAM S.; KELLY K.; MOLLENKAMP C. Hedge Funds Try Career Trade Against Euro. The Wall Street Journal, [S. L.], 2010. Disponivel em: <http://online. wsj.com/news/articles/SB1000142405274870379500 4575087741848074392>. Acesso em: 26 fev. 2010.

REDAZIONE. C. D. S. Piano straordinario per salvare l'euro Trichet avverte: "Crisi sistemica". Corriere della sera, [S. L.], 2010. Disponivel em: <http://www.corriere.it/>. Acesso em: 08 maio 2010.
SCHETTINO, F. Monete bucate e carta straccia, La contraddizione, [S. L.], n.133, 2010.

ZETTELMEYER, J.; TREBESCH, C.; GULATI, G. The Greek debt exchange: An autopsy. Available at, [S. L.], 2012.

NOTAS

1 Portugal, Irlanda, Italia, Grécia, Espanha.

2 A previsão do PIB Italiano, ano 2013 , foi $-1,8 \%$ pelo S\&P (REUTERS ITALIA, 2013).

3 Mais exatamente desde a primeira grande crise do dolar Eua do segundo pós-guerra, que coincidiu com a anulação unilateral dos acordos de Bretton Woods, veja-se PALA, 1997.

4 Agora como nunca ante é correto afirmar que "o verdadeiro limite da produçao capitalista é o proprio capital" (MARX, Il capitale, III;15).

Francesco Schettino

Assistant Professor da Seconda Università di Napoli E-mail: francesco.schettino@unina2.it

Seconda Università di Napoli Dipartimento di Giurisprudenza Via Mazzocchi, 5 - S.Maria Capua Vetere (CE), 81055 